http://dx.doi.org/10.4314/ejotmas.v7i1-2.19

\title{
THE USE OF SPECIFIC LINGUISTIC FEATURES WITHIN THE CONTEXT OF A CASUAL CONVERSATION IN A SPEECH COMMUNITY
}

*Ekiyokere EKIYE

\begin{abstract}
There seems to be nothing remarkable about the interaction between two interlocutors who have never been in contact with each other. These persons are able to understand themselves in contact situations because most times, a common language of communication is known that can sustain the exchange for the time necessary. However, when such exchange is between individuals with some level of contact or familiarity, the concept of speech community comes into play. The concept is useful but may be problematic at times and one cannot avoid applying this idea when trying to make sense of the process that takes place in the conversation, specifically a causal conversation. The aim of this sociolinguistic study is to explain how individuals are able to build social history, construct interactional talk, maintain relations with each other and reinforce solidarity from a two hour audio recorded conversation (ARC) between an ethnic Indian and a Nigerian in Marylebone, London using interactional socio-linguistic and conversation analytic. By doing so, the concept of a speech community as well as how a group can be identified as being members of a community is understood. A particular focus is paid to such linguistic features as the register of conversation, turn taking, discourse variation, phonological variation and grammatical variation characteristic of London, Nigerian and Indian English observed in the speech of the participants and how these features function to build and maintain relations.
\end{abstract}

Keywords: Speech community, Casual conversation, Linguistic features, Sociolinguistics, ARC

\section{Introduction}

Nothing appears to be significant about the interaction between two interlocutors who are not familiar with each other.In such contact

*Ekiyokere EKIYE is of the Department of English and Communication Studies, Faculty of Humanities and Social Sciences, Federal University, Otuoke, Nigeria

Email: ekiblack2@yahoo.com 
circumstances, these people are able to comprehend themselves because a prevalent language of interaction is often recognized that can support the exchange for the needed moment.However, the notion of speech community comes into play when such exchange is between the persons with some level of contact or familiarity. The concept is useful but can sometimes be problematic and we cannot play down on this idea when attempting to comprehend the process taking place in discussion, especially in the context of a causal discussion between friends. Most literature that have looked into the sociolinguistics of language use between friends or small close-knit groups agree on the fact that language functions as a channel for building and maintaining distinct identities and social relations (DeCapua \& Boxer 1999; Tannen 1993; Kong 2003). Specifically, several scholars (Coates 1996; Tannen 1984; Apter \& Josselson 1998; Johnson \& Aries 1998) have documented the significance of casual conversations between friends to build, establish and maintain friendships.

Unlike other studies, the current study documents the casual conversation between friends with the aim of understanding the concept of a speech community. It seeks to identify the unique language featuresused byinterlocutors that mark them as being members of a speech community, and then examine how these features functionto build social history, construct interactional talk, maintain relations with each other and reinforce solidarity in a casual context interaction. The data for this study was collected from a two hour audio recording of a conversation. The next section discusses the concept of speech community, followed by a casual conversation and ends with the section on interactional versus transactional talk.

\section{Speech Community}

The concept of speech community plays a role in a number of social sciences like anthropology, sociolinguistics, sociology and psychology. While researchers who investigate issues relating to migration and ethnic identity use social community theories to understand how migrants assimilate into societies, sociolinguists like John Gurmperz use the notion to understand how intimate conversations can influence ways of speaking and interpretation.A speech community refers as a group of individuals who have come to share similar rules or norms concerning language use because of frequent interaction with each other. Put another way, a speech community can refer to persons whose language use is unique and mutually intelligible among them. Such groups can be made up of individuals with shared hobbies, interests or lifestyles, close knit groups like families, friends or even members of the same profession with a specialised speech style or register. 
Saville-Troike (2003) distinguishes between "hard-shelled" communities which appear to be intimate and insular, example a family and a "softshelled where a lot of interaction takes place. She argues that a speech community could also be one that use a common language as English, which is spoken as a global language. Saville-Troike's viewpoint of a speech community was criticised as being too vague because a true speech community cannot be described based on just the use of a common language. Salzmann (2004) on the other hand opines that interlocutors who speak a common language do not always form members of a speech community. Two individuals from two ethnic origins could share a common language like French, but the respective varieties of French and the rules for speaking them are largely unique to identify the two populations with different speech communities (Salzmann, 2004). He states instead that a speech community should be identified narrowly based on such linguisticfeatures as grammar, manner of speaking, pronunciation and vocabulary. Salzmann's standpoint is adopted in the current study.

\section{Casual Conversation}

The importance of casual conversation in forming, strengthening and maintaining lasting social relationships and identity amongst friends has been adequately documented (e.g., Coates, 1996; Tannen, 1984). Casual conversation describes any kind of linguistic exchange that is informal and spontaneous, and involves interlocutors who share equal social status and all speakers possess same right to maintain the floor and control the topics of discourse (Cameron, 2000; Eggins \& Slade, 1997). Unlike formal or institutional interactions, casual conversation is naturally informal and the parties involved collaborate to construct talk (Drew and Heritage, 1992). Casual interaction among friends emphasizes exchange consisting of reciprocal as well as collaborative work that varies according to familiarity among the parties involved or level of intimacy and setting. It involves sharing and divulging of personal information, oftentimes by way of narratives that reflect and complement the other interlocutor's narrative (Goffman, 1974). Apart from spontaneous speech, another peculiar feature of casual interaction is overlaps. It is pertinent to mention also that for friends, as will be seen in this study, casual conversation tends to take on many of the features that can be categorised as interactional rather than transactional.

\section{Overlaps and Turn-taking}

Turn-taking units allow smooth conversation between participants without everyone speaking at the same time (Sack et al., 1974). Writing 
in 1981, Edelsky observes that there are two types of floors in talk in academic meeting: single floor and collaborative floor. The single floor has to do with the orderly management of talk or formal turn-taking of one interlocutor to another. However, when turn-taking rules are overridden, it can be interpreted as face-threatening acts, interruptions or struggle for control within the speech event. Collaborative floor on the other hand, has the floor opened to all participants simultaneously, characterised by supportive overlaps, repetitions and brief turns than observed in single floor. However, Edelsky's study seems to focus on floor-holding in formal speech situations and as such, it does not account for the collaborative function of simultaneous speech and overlaps in casual conversation.

Research on everyday social conversations (Tannen 1984; 1993) show that such interactions are collaboratively constructed; most times through casual simultaneous speech and overlaps, without the negative implications pointed out in formal turn-taking speech events. Rather, "simultaneous speech and overlaps are cooperative mechanisms that serve to emphasize the shared meanings, the shared history, the background knowledge, and degree of intimacy shared by the interlocutors and to strengthen their bonds of friendship" (Decapua and Boxer, 2006). It follows then that for friends engaging in informal casual conversation, the presence of simultaneous speech, overlaps as well as unstructured turn-taking is important for the aim of constructing discourse collaboratively. Thus, conversation is a jointactivity, formed via the collaborativeefforts of all the participants and the greater the intimacy among them, the more overlaps serve to hold and strengthen already existing personal relations.

\section{Interactional Vs Transactional Conversation}

As aforementioned, a casual conversation between friends takes on features that are categorised as either interactional or transactional. In such exchange, information divulged often replicates one another (Coates, 1996) or one participant's talk is followed by a similar experience or by an experience concentrating on a particular topic emerging from a previous topic. $65 \%$ of casual interactions between friends are spent on social topics which serve to strengthen social bonds or help friends keep track of other members within their speech communities (Dunbar, 2004, p.105). Also, intimacy among participants who engage in casual conversations plays a major role. This is because, the greater the level of intimacy, the more participants are able to engage in interactional talk as they have a feeling of shared background and meaning, thereby creating room for presumed shared information, experiences or situations and reference to people and 
details based on shared history.Conversely, transactional talk evolves from low levels of intimacy between interlocutors and the lower the degree of intimacy, the more participants are expected to spend time on transactional talk to help them construct relationships and build relational identities. As far as social status is concerned, talk or conversation between participants who are of equal status is typically interactional and they display relational identities rather than development, which is only observed when there is social distance with participants engaging more in transactional talk.

\section{Discussion}

As previously stated under the section on speech community, this discussion is done in line with Salzmann's (2004) parameters for identifying and analysing a speech community. The Participants of this study were two male friends, with Nigerian and Indian ethnic origin and they had been in regular contact for a period of ten (10) years. The two friends fall within the same age bracket (21-22) and the conversation between them was held in Marylebone, London. The two hour audio recording of the conversation between Hritik and Ebenador was analysed using interactional socio-linguistic and conversation analytic to give perspectives on the concept of a speech community. In line with Goffman (1983), the speech event shown by members of this speech community is that of initiation to closure. To buttress, the speech event (a lunch date) and the social distance relationship (friends) were the social variables observed. The type of activity and social distance informed the extent to which interactional talk was carried out by the participants. Conversation analysis exposed unique speech patterns between both participants as they collaboratively contributed to the conversation.

\section{The Linguistic Features}

\section{Register}

A register is the kind of language used for a specific purpose or in a specific social context. Wardhaugh and Fuller (2006, p.53) describe registers as "sets of language items associated with discrete occupational or social groups". Registers most often are determined by the context in which a conversation takes place. For instance, when speaking in a formal setting, as opposed to an informal setting, it is likely that a speaker will use more features of standard grammar and refrain from the use of non-standard forms like contractions (like ain't) or slangs in their utterances. The conversation between the members of this speech community was held in an informal context (McDonald's 
restaurant). Moreover, because Hrtik and Ebenador are close friends, the tenor of their conversation tends to be informal.

This is evident in the great deal of laughter present in the recording. Also, the mode of their conversation is spoken and not written. As it is a spoken conversation which is not planned, there is high level of simultaneous speech between Ebenador and Hritik. Unlike the spoken mode of conversation which is characterised by hesitations, pauses or other distinct linguistic features, the written mode tends to be more formal, even between close friends, as there is usually a preplanned purpose for the discourse rather than just phatic communication. With reference to the field of discourse, the recorded data includes a number of topics which either flow from one subject to another or revolve around a topic brought up by any of the members within this speech community. Both members of this speech community are Accounting students at Westminster Business School, thus at some point when Ebenador and Hritik talk about the best way to have a career in accounting, they use accounting register. An example of this is seen in the excerpt below:

Excerpt 1 - (Ebes and Hritik are talking about pursuing a career in managerial accounting)

01 Hritik: $\quad$ Come there <.> it's a suitable [career

02 Ebes: [The most productive way is

03 Hritik: [Managerial accounting

04 Ebes: [The best as it does two things, one is <.> audit

05 [and

06 Hritik: [Yeah@@ @ what of xx

07 Ebes: [Build up in liquidation too be::cause

08 Hritik: [Yeah liquidation coz time <.> now to catch those fraudsters@@

09 Ebes: @@@ them making all the liquids @@

Excerpt one shows instances of language use specific to the accounting profession, and which other individuals outside this profession may not understand easily. For instance, when Ebes talks about audit in line 04, he is referring to 'an independent examination of the financial statements of a company'. Another example is seen in lines 07 and 08 where Ebes and Hritik use the term liquidation to refer to 'the process of closing down a company' and line 09 in which Ebes refers to 'physical cash' as liquids. As earlier stated, both members of this speech community are accounting students and so, this particular topic is specific to their profession but not at a very formal level. Since 
both participants are colleagues of equal status having a casual conversation over lunch in McDonalds, Ebes and Hritik's conversation would fall under the category of interactional talk; because they are communicating to maintain social relationships with each other (Thornbury, 2005). At one point, Hritik and Bara start talking about their friend, Mahmud, as seen in the excerpt below:

Excerpt 2 - (Ebes and Hritik are talking about Mahmud's absence from the university)

01 Hritik: You know this th<.>ing man? About Mah[mud

02 Ebes: [dumb fuck no serious with books innit

03 Hritik: @ you know that guy um:: does have a lot of noggy excuses and he is

04 driving us barmy yeah [as well

05 Ebes: [noggy, barmy @@@ some rhymes man@@ our yute will

06 be alright, man just gotta buckle up

07 Hritik: you know, buckle up

The conversation above is typical of what Dunbar (2004) calls gossip because both Ebes and Hritik are talking about Mahmud in his absence. However, the discussion is not negative as they are only expressing personal concerns about Mahmud's absence from classes and his studies. Hence, it should be viewed as an instance of phatic communication which constitutes much of daily interactions between friends. Although the use of words like 'dumb' in line 02 by Ebes may be interpreted as negative to other individuals, to the members of this speech community (even if Mahmud were present) it is harmless because they are friends and understand it is not an insult. In line 05 however, Ebes says our yute will be alright, man just gotta buckle up that is, 'our friend will be alright he just needs to buckle up' and Hritik agrees with his final statement in line 07 . In this particular situation, while both members of this speech community are spending time together over launch, they use gossip positively to keep track of their friend who is also a member of their social group.

The members of this speech community also make use of slangs in their conversation.An example is seen in lines 03 and 04 where Hritik uses Brummie slangs like noggy to refer to 'outdated' excuses and barmy to mean'insane'. Another example is seen in line 05 when Ebes uses the word yute which is a Jamaican slang for 'friend'. According to Elbe (1996), slang is "an ever changing set of colloquial words and phrases that speakers use to establish or reinforce social 
identity or cohesiveness within a group or with a trend or fashion in society at large" (cited in Reyes, 2005, p.511).Rampton (1999) suggests that most times, "people use language and dialect in discursive practice to appropriate, explore, reproduce or challenge influential images and stereotypes of groups that they don't themselves (straightforwardly) belong to" (cited in Reyes, 2005, p.510). Both members of this speech community have lived in the UK for some time but in different locations. Hritik has lived in Birmingham for seven years and recently moved to London to study for a Master's degree in Accounting and Finance. It is possible that Hritik is trying to index his identity as a 'Brummie' when he uses slangs that are associated with the city of Birmingham.

It is a similar case with Ebenador who lives in Finsbury Park and where there is a high Jamaican population. Considering the fact that he has lived in this area for five years, Ebenador must have associated regularly with the Jamaicans in this area. Like Hritik, he may have used Jamaican slang because he is trying to construct his identity as being one of them. Also, the word man seems to be used as slang within the context of this conversation, as observed in the utterances of Hritik in line 01 and Ebes in line 05. Rather than calling each other by their real names, both participants use man as an identity marker which reinforces solidarity between both interlocutors in this speech community. This may seem odd to other individuals, but not in this speech community because due to regular socialization, they have come to share similar ideologies regarding this particular language use.

Again, Hritik and Ebes frequently use facial expressions like smiling or gestures like 'grinning with the teeth' to indicate that a lady looks sexy and other non-verbal communication like raising to eyebrow to indicate 'surprise', nodding to show 'agreement or negation' within this speech community.

\section{Turn-taking}

As far as turn-taking within this speech community is concerned, a marked feature is the high rate of spontaneous speech that occurs between Ebes and Hritik. There are few occasions though when one member holds the floor and the other listens and offers support using minimal responses. Minimal responses are supportive speech devices produced by a listener to signal active participation in a conversation (Coates, 1989). As aforementioned, the conversation between the members of this speech community takes place in McDonald's, which is a very sociable and convenient setting for an informal interaction. The excerpt below shows instances of minimal responses observed in this speech community. 
Excerpt 3 - (Ebes is telling Hritik about paying his rent and a man he met at the pub)

01 Ebes: The stuff has been in my head for some time now <latch>

02 Hritik: Bosting!

03 Ebes: I think I better get down to it and re::Iax

04 Hritik: $\quad H m m<.>$ you should

05 Ebes: $\quad$ You know <.> it's a lot of liquids though

06 Hritik: Mmm

07 Ebes: $\quad$ Oh yeah, met Mark at the pub over the weekend <..> Man was drunk for sure

08 he kept talking nonsense, couldn't keep up

09 Hritik: @@@ So what you did?

010 Ebes: No damn thing man @ just left him there @@

In the excerpt above, the turn-taking procedure is highly regulated as a speaker only contributes when one speaker's turn ends or when his opinion is solicited. Here, Ebes is sharing personal information about paying six months' rent to his landlord and seeks Hritik's agreement on the decision he has taken. In turn, Hritik responds using supportive positive feedbacks (minimal responses) like boisting (brilliant), $\mathrm{hmm}$ and $\mathrm{mmm}$ in lines 02,04 and 06 . For a small speech community where the conversation in a casual context is probably focused on group solidarity, Hritik seems to use minimal responses to indicate that he is actively participating or showing alignment in the conversation. Excerpt four on the other hand shows instances of spontaneous speech between Hritik and Ebes.

Excerpt 4 - (Ebes and Hritik are talking about football)

01 Hrithik: Manchester coach should be [sacked

02 Ebes: [Get outta here, he won more two leagues @@

03 Hrithik: [@Mourinho should be the new coach @@

04 Ebes: [What, that loser, we not gonna get cups yute

05 Hritik: [Mourinho has won over ten leagues with

06 Chelsea, Madrid, FC porto and Intermillan that are among the best teams in the

$07 \quad$ World and its damn sure we'll win some <.> thing the first two years, so

08 [Mourinho @

09 Ebes: $\quad$ [Yeah, Mourinho should take on ManUnited @@ 
The conversation in the excerpt above is an example of what Tannen (1994, p63) terms as a "high involvement" speech in which speakers interact at a fast, overlapping speed. The way the members of this speech community tend to interrupt each other's utterances appears aggressive, as the overlaps do not occur at transition relevant places, that is, at the end of a clause or phrase. However, not all spontaneous speech is a struggle for dominance and overlaps can signal solidarity and connection between speakers. This is the case between the members of this speech community and the amount of laughter noticed between Ebesand Hritik in the conversation signals that this is typical banter between friends. Coates (1989, p.107) identified seven kinds of simultaneous speech, some of which are not efforts to encroach on the existing speaker's right to a turn. From the excerpt, the common type of simultaneous speech observed is the one where each speaker seems to self-select during the conversation. In line 01, Hritik begins his statement with his opinion that "Manchester coach should be sacked". It also seems as if they have had this conversation before because Hritik has not even completed his sentence before Ebes counters him in line 02 to state his stand on the club's coach that "... he won more two leagues". In lines 03 and 04 , both Ebes and Hritik practically speak at the same time. But in line 05, Hritik brags about Mourinho's achievements, stating that with Mourinho in the club, they will win something in two years. He is finally supported by Bara in line 09 "Yeah, Mourinho should take on ManUnited", reiterating Hritik's final statement. A close examination of the conversation between Hritik and Ebes reveals that both members of this speech community do not view each other's utterances as competitive, rather, they both respond to the contents of each speaker's contribution while supporting each other with back-channels like 'yeah'. In the end, they collaboratively reach an agreement regarding the topic under discussion.

\section{Discourse features}

On the aspect of discourse features within this speech community, one marked feature is the use of the invariant conversation tag, innit, by both interlocutors. The invariant conversation tag, innit, is a feature of London Cockney speech which is thought to have evolved from Creole or Indian English (Rampton, 1995, p.127). Though its use was mostly associated with the working class speech, it is believed to have spread to the speech of higher working class population in other parts of London (Anderson, 2001). The invariant utterance tag seems to occur frequently in the speech of Ebenador and Hritik. An instance is seen below: 
Excerpt 5 - (Hritik and Ebes are talking about different topics)

01 Hritik: You going to Nigeria for Christmas innit<..>you see chicks in safaris innit

02 Ebes: Fucking cock, we got them fly beauties in shabbies @@ innit

03 Hritik: Shit, I got to run to the computer room for FIS still got some blasting to do you know

04 Ebes: Was gonna say so last time we dropped from the train but saw them fly

$05 \quad$ chicks@@

06 Hritik: @@ saw them blondees forming innit @@ here (clears throat) drink

07 drink this

08 Ebes: Thanks man, I don't need nofuzzie to calm [down @

09 Hritik: [Yeah? @@

In lines 01 and 02, Ebes and Hritik are talking about the Christmas holiday and girls in Nigeria. The use of innit in line 01 indicates that Hritik expects Ebes to agree with his statement. Ebes replies Hritik in line 02 but this time, he uses innit as an assertive terminal marker to indicate agreement. It appears that in this speech community, innit is used to signal openness in the conversation and its occurrence in the utterances of both Ebes and Hritik may be because they prefer it as an important discourse marker used to maintain solidarity or cohesiveness between them.

\section{Lexical Features}

Regarding lexical features, a marked feature is that certain words are used with different meanings (that is, connotatively) within this speech community. For instance, when Hritik talks about the FIS (Financial Information System) assignment he had to complete in excerpt 05, line 03, he said, "shit, I got to run to the café for FIS, still got some punching to do you know". The lexical item blasting seems to be used connotatively to mean 'the act of typing" rather than its literal meaning in Standard English, that is, 'to make a loud noise'. Another example is the lexical item fly used by Ebes in line 04 as a discourse metaphor to mean 'beautiful' and not its literal meaning in Standard English, that is, 'to either travel by air or to suspend in the air'. There is also the word forming which is used metaphorically in line 06 to mean 'the act of showing off' rather than its denotative meaning 'to create.' 
The final example is the lexical item droppedin line 04 which seems to connote "the act of alighting or getting from a train". It is not clear if such uses are linguistic influences from Hritik and Ebes' respective countries where they learnt the English language, because these will certainly be interpreted differently by other English speakers outside this speech community. But, the fact both participants understand the meanings of these words signal their social relationship as friends. A possible explanation for this marked feature observed in Ebenador and Hritik's utterances is that they may have deliberately used the words as discourse metaphors to show covert prestige that is, the lexical items are used connotatively to maintain their distinct identities from the larger English-speaking community.

\section{Phonological Features}

The differences observed between the participants in this speech community are mostly at the level of phonology. Although Ebenador and Hritik have lived in the UK for some time, the different geographical locations (India and Nigeria) in which they grew up seem to have affected their realisation of certain sounds. Linguistic variation at the phonological level deals with the different realisations of a particular sound by different individuals. Such distinct realisations are known as variants (Wardhaugh \& Fuller, 2015, p.149). One of the marked phonological features noticed in this speech community is two variant, that is, $\left[\mathrm{t}^{\mathrm{h}}\right]$ and $[\mathrm{t}]$ for the voiceless dental fricative $/ \theta /$. For example, when Hritik asked Ebes a question in excerpt 2, line 01: "You know this $\mathrm{t}<$.> hing man?" he realised the variable /t/ in thing as a voiceless aspirated alveolar plosive [ $\left.\mathrm{t}^{\mathrm{h}}\right]$. Ebes realised it a non-aspirated voiceless alveolar plosive[t] in excerpt 1 , line 05 when he says "...Things ...". Also, the voiced velar nasal / $\mathrm{\eta} /$ which occurs at the end of the word thing was realised together with the voiced uvular plosive $/ \mathrm{g} /$, that is, [thing] unlike British English where the variable $/ \mathrm{g} /$ is dropped, as in / $\theta \mathrm{in} /$. These realisations are common features of Indian English (Trughill and Hannah, 1994) and a possible reason for the different realisations of the $/ \theta /$ and $/ \mathrm{g} /$ variables on Hritik's part is because he grew up in India where such realisations are unmarked.

Another marked phonological features noticed in Ebes's speech is one variant for the voiceless post-alveolar fricative/[/. For instance, at some point in the conversation, when Ebes says "I need salmon fish". The variable /j/ which occurs at the word-final position in the word fish was realised as a voiceless alveolar fricative /s/ that is, [fis] unlike Standard English where it would be realised as /fij/. Another marked feature in Ebes' speech is the realisation of the voiced palatoalveolar affricate/d $3 /$ as a voiced post-alveolar fricative/z/ which occurs 
in medial positions in words like 'judge' and 'treasure'. Finally, Ebes tends to realise the / $/$ / variable in words like them as [d] that is, a voiced alveolar plosive and the /t// variable in words 'church' and 'cheap' is realised as a voiceless alveolar fricative [s]. Like those observed in Hritiks utterances, these realisations are common in the English of Nigerians who reside in the Southern region of Nigeria. Thus, it can be suggested that Ebes realises those phonological variables differently because he grew up in that region of Nigeria where they are not marked.

\section{Grammatical Features}

The grammatical level (which constitutes morphology and syntax) is another aspect where variation is displayed by both interlocutors. Grammatical variation deals with the differences in the structure of words and sentences observed in the utterances of the members of this speech community. On the aspect of syntactic variation, one of the marked features is the absence of subject-verb inversion in interrogative sentences, especially in Hritik's utterances. At one point in the conversation, Hritik and Ebes began making arrangements to meet at Trafalgar Square on Christmas Eve and Hritik asks Ebes, what you will like to bring?, and who you will arrive with? In both sentences, the second person personal pronoun, you, takes the position of the modal verb, will. Such realisations may be described as deviations from Standard English in which the sentences would be re-produced as 'what will you like to bring' and 'who will you arrive with'. But this is not the case because such realisations point to the fact that people speak English differently in other regions. Hritik also tends to use 'itself' to mark emphasis at the end of interrogative questions. For instance, Hey man, can we meet at Trafalgar Square on Christmas Eve itself? Considering the fact that Hritik is not a native speaker of the English language, such distinct grammatical realisations may be a result of the linguistic influence from his first language, Hindi or the word order in Indian English.

Another syntactic variation observed in this speech community is the use of negative concord. Negative concord describes structures in which negation is realised by using two or more negative linguistic units. Eckert (2000, p.119) comments that, negative concord is "arguably the most conscious and stigmatized non-standard variable" due to its prolonged association with non-standard English. In London, it has been observed that negative concord is a feature of Jamaica English (Sebba, 1993). Negative concord was mostly noticed in Ebes' speech. For instance, in excerpt 5, line 08, Ebes says, "thanks man, I don't need no fuzzie to calm down". As aforementioned, Ebes has 
lived in Finsbury Park for five years and irrespective of the stigmatised nature of 'double negatives', he may have adopted this speech style because of its positive association with the Jamaica population in Finsbury. As Hewitt (1986, p.102) puts it, "despite the wider social stigmatisation..., the distinctive language of black youth culture is in fact a 'prestige variety' among many young people".

\section{Conclusion}

This study sort to understand the concept of speech community by analysing certain linguistic features observed in the casual conversation of two (2) friends and how those linguistic characteristics (such as discourse variation, phonological variation, etc.) have been employed to develop unique speech patterns thatare only understood by persons who havebeen in contact for a prolonged period. The conversation between the participants of this study can be described as successful because both participants are able to collaboratively construct interactional talk, thereby exposing relational identity between them as close friends. This in turn not only aids to build, maintain and reinforce solidarity between them but it also results in the enactments of friendships amongst them. There are elements of parts of conversation that are only used and understood by the participants as a result of shared knowledge. Thisshared knowledge is highlighted in the similar realisation of some linguistic features. However, the differences in the realisation of other linguistic forms observed in the speech of both friends are indicative of their distinct regions of upbringing and also highlight their individuality. But,the fact that both friends are able to understand each other irrespective of such partial differences and have even been able to establish codes peculiar to themselves, but exclude membersof the wider language community, point them out as being members of the same speech community. This paper concludes therefore that, a speech community is not only one where its members relate in a common language but, it is also one with individuals, who overtime have come to develop similar speech patterns based on several linguistic parameters even with their individual differences that are unique or unmarked to them, but unpopular or interpreted as marked/non-standard to those in the widerlanguage society. 


\section{References}

Andersen, G. (2001). Pragmatic markers and sociolinguistic variation: A relevance-theoretic approach to the language of adolescents. Amsterdam: John Benjamins.

Apter, T \& Ruthellen, J. (1998). The pleasures and perils of girls' and women's friendships. New York: Random House.

Cameron, D. (2000). Good to talk? Living and working in a communication culture. London: Sage.

Coates, J. (1989). Gossip revisited: language in all-female groups. In Cameron, D. \&

Coates, J. (Eds.). Women in their speech communities (pp.94-122). London: Longman.

DeCapua, A. et al. (2006). Women talk revisited: Personal disclosures alignment. Development, 25, 393-412.

DeCapua, A. and Diana, B. (1999). Bragging, boasting and bravado: Male banter in the workplace. Women and Language, 22, 5II.

Dunbar, R. (2004). Gossip in evolutionary perspective. Review of General Psychology, 8(2), 100-110.

Drew, P. and John, H. (Eds.). (1992). Talk at work. Cambridge: Cambridge University Press.

Eckert, P. (2000). Linguistic variation as social practice: The linguistic construction of identity in Belten High. Oxford: Blackwell.

Edelsky, C. (1981). Who's got the floor? Language in Society, 10, 383-421.

Eggins, S. \& Diana, S. (1997). Analysing casual conversation. London: Cassell.

Goffman, E. (1983). Forms of talk.Philadelphia: University of Pennsylvania Press.

. (1974). Frame analysis. New York: Harper and Row.

Hewitt, R. (1986). White talk, black talk: Inter-racial friendship and communication amongst Adolescents. Cambridge: Cambridge University Press.

Jenkins, J. (2007). English as a lingua franca: Attitudes and identity. Oxford: Oxford University Press.

Johnson, F. \& Elizabeth, A. (1998). The talk of women friends. In Coates, J. (Ed.). Language and gender. Oxford: Blackwell, 215- 225.

Kong, K. (2003). 'Are you my friend?': Negotiating friendship in conversations between network marketers and their prospects. Language in Society, 32, 487- 522.

Rampton, B. (1995). Crossing: Language and ethnicity among adolescents. London: Longman. 
Reyes, A. (2005). Appropriation of African American slang by Asian American youths. Journal of Sociolinguistics, 9 (4), 509-532.

Sacks, H., Schegloff, E. \& Jefferson, G. (1974). A simplest systematics for the organization of turn-taking in conversation. Language, 50(4), 696-735.

Sebba, M. (1993). London Jamaican. London: Longman.

Saville-Troike, M. (2003).The ethnography of communication: An introduction. $3^{\text {rd }}$ ed. Blackwell.

Salzmann, Z. (2004). Language, culture and society: An introduction to linguistic anthropology. New York: Westview.

Tannen, D. (1994). Gender and discourse. Oxford: Oxford University Press.

Tannen, D. (1993). Framing in discourse. Oxford: Oxford University Press.

Tannen, D. (1984). Conversational style: Analyzing talk among friends. Norwood, New Jersey: Ablex.

Thornbury, S. (2005). Beyond the sentence. Oxford: OxforUniversity Press.

Wardhaugh, R. \& Fuller, M.J. (2015). An introduction to sociolinguistics, 7th ed. West Sussex: Wiley \& Sons. 